\title{
ROJO Y NEGRO: \\ MILITARES Y ECLESIÁSTICOS EN LA CONSUMACIÓN DE LA INDEPENDENCIA DE MÉXICO
}

\author{
RED AND BLACK: \\ THE MILITARY AND THE ECCLESIASTICS IN THE CONSUMMATION \\ OF THE INDEPENDENCE OF MEXICO
}

\author{
Guadalupe Jiménez Codinach \\ Universidad Iberoamericana \\ rosacodinach@yahoo.com.mx
}

\begin{abstract}
This work attemps to answer the question: can the role of the army and clergy in the last stage of New Spain's War of Independence (1820-1821) be characterized as retrograde, illiberal and unconstitutional? We argue that in this period, the birth of Mexico as an independent nation and sovereign state, was not the product of a counterrevolution or the machinations of two regressive groups -army and clergy-concerned only with their privileges, but part of a revolutionary wave in the Atlantic region during the years 1820-1823. Indeed, forward-thinking, socially -conscious and freedom- loving individuals participated in México's Independence in 1821.
\end{abstract}

Keywords: Independence of New Spain, military, ecclesiastical, Iturbide counterrevolution, independent Mexico.

\section{Resumen}

Este trabajo intenta responder la siguiente pregunta: ¿̇la participación de militares y eclesiásticos en la última etapa de la guerra de independencia de la Nueva España se puede caracterizar, como muchos la han descrito, de retrógrada, conservadora, antiliberal y anticonstitucional? En estos años fundacionales, el nacimiento de México como nación independiente y Estado soberano no fue producto de una contrarrevolución ni de maquinaciones de dos grupos retrógrados -militares y clero-, preocupados sólo de sus fueros y privilegios, pues entre sus filas, de 1808 a 1821, se encuentran personas de ideas avanzadas, de conciencia social, de amor a la libertad.

Palabras clave: Independencia de Nueva España, militares, eclesiásticos, contrarrevolución de Iturbide, México independiente. 


\section{Introducción: casacas y sotanas}

En su famosa novela Le Rouge et le Noir (1831) el autor Henri Bayle (1783-1842), bajo el seudónimo de Stendhal, describe la década de 1820 a 1830 en Francia. Su protagonista, Julián Sorel, es un ambicioso joven que quiere salir de la pobreza y de su infeliz vida familiar. Para lograrlo, intenta primero ser sacerdote y después abraza la carrera militar. El rojo representa el color de las casacas militares y el negro las sotanas clericales. Esos serían dos destinos que lo sacarían de la miseria y que le darían un lugar distinguido en la sociedad. "Es evidente -afirma Julián sobre su labor como preceptor de unos niños- que aquí puedo ganar unos miles de francos y emprender luego con mayores ventajas la carrera militar o la eclesiástica, según la moda que impere en Francia en ese momento" (Stendhal, 2015: 158). Admirador clandestino del emperador Napoleón I, Julián representa a miles de oficiales y soldados veteranos de las guerras napoleónicas y de las de independencia en la América española, cansados de las fatigas de la guerra, de la precariedad y mala vida en los cuarteles, del fragor de las batallas pero a la vez admiradores de un oscuro cadete descrito por su biógrafo Patrice Gueniffey de la siguiente manera: "Napoleón nace en la guerra. En ella muestra sus cualidades, un temperamento, un carisma, incluso un estilo sin par que no se encuentra en épocas posteriores" (Gueniffey, 2018: 156).

En el caso de la Nueva España postrera, casacas y sotanas no sólo aparecerán en la oleada revolucionaria atlántica de 1820, sino que estuvieron presentes de 1808 hasta 1821, tanto entre los que deseaban la independencia como en los que defendían el gobierno virreinal y serían también parte de la gran mayoría de los revolucionados, a fuerza, neutrales en la contienda, pero víctimas de la violencia y destrucción de la guerra civil de 11 años. Por ello no sorprende su participación en la consumación de la independencia de Nueva España lograda por el Ejército Trigarante y con el apoyo del clero diocesano y regular, así como de un pueblo cansado de años de sufrimiento y privaciones.

\section{Polvos de aquellos lodos}

A fines del siglo $X X$, el historiador Luis González y González declaró en una entrevista de prensa:

Yo comparto la idea, junto con otros historiadores, de que en este país las épocas de avance, aunque sea lento, son las pacíficas. Hasta ahorita ningún período violento ha traído consecuencias positivas en el aspecto económico o en el político (Rivera, 1999).

Esta reflexión puede corroborarse en la paciente investigación de cantidad de archivos y obras sobre el período 1808-1821. Una mirada a los actores de las sucesivas etapas de intentos emancipadores revela que la violencia desatada, el enfrentamiento entre vecinos y miembros de una misma familia; la destrucción de edificios, casas, silos y alhóndigas; la inundación de minas; la quema de cosechas; la invasión de haciendas y ranchos; la desaparición de puentes; la quema de libros, manuscritos, impresos y prensa; la clausura de escuelas; el abandono de iglesias, hospitales; el vandalismo de imágenes y obras de arte; la muerte de cerca de un millón de personas; la aniquilación de ganados caballar, vacuno y lanar; la escasez de alimentos, medicinas y mercancías, en medio de la zozobra y el terror de hombres, mujeres y niños, conformaron años de destrucción que no adelantó el logro de la independencia, sino que la dificultó.

En este artículo se intenta responder a la siguiente pregunta: ¿la participación de militares y de eclesiásticos en la última etapa de la guerra de independencia se puede caracterizar, como muchos la han descrito, de retrógrada, conservadora, antiliberal y anticonstitucional? ¿Cómo fue realizada por la oligarquía, palabra inexistente en 1820-1821?

Si observamos lo sucedido en los principales momentos del proceso emancipador, entre 1808 y 1821, nos encontraremos con otra realidad: el continuo papel activo de 
militares regulares o de milicias, de clérigos diocesanos y de miembros de órdenes religiosas en los esfuerzos por independizar la Nueva España y convertirla en una nación libre y soberana, y cómo sus ideas y obras continuaron presentes en la trigarancia.

Se ha descrito al movimiento trigarante como una "contrarrevolución" en la que dos grupos, los militares y el clero, "(...) opuestos a la restauración de la Constitución de Cádiz en la Monarquía española”, lograron consumar la independencia a contracorriente de los ideales y esfuerzos iniciados desde 1808, continuados en 1809, 1810-1815 y 1816-20. Martín Quirarte Ilama a la etapa de la Consumación "La Contrarrevolución de Iturbide" (1995: 71) y así lo sostiene la obra de Romeo Flores Caballero (1969). ${ }^{1}$ En resumen, estas obras explican la consumación como el resultado de aquellos que se opusieron a la insurgencia y que fueron ajenos a los proyectos de independencia en los 13 años transcurridos de 1808 a 1821.

Este trabajo académico intenta aclarar y explicar lo sucedido en estos años fundacionales del nacimiento de México como nación independiente y Estado soberano, en mi opinión, muy lejos de esta caracterización del movimiento trigarante como producto del triunfo de una contrarrevolución, de las maquinaciones de dos grupos retrógrados -los militares y el clero-, preocupados sólo de sus fueros y privilegios. Si es, como se afirma temerariamente, que el grupo triunfador en la consumación de 1821 fue el constituido por los militares y el clero, ambos retardatarios y movilizados en defensa de sus intereses -falacia repetida hasta el día de hoy- ¿ambos grupos se pueden definir como radicalmente opuestos a la independencia?, ¿contrarios a los planteamientos de los criollos del Ayuntamiento de la Ciudad de México en 1808?, ¿̇a los objetivos de Allende e Hidalgo en 1810 y 1811?, ¿a los esfuerzos de Ignacio López Rayón y de la Junta de Zitácuaro?, ¿a los trabajos y los días de José María Morelos, del Congreso

1 Asimismo, una revisión del libro Revolución y Contrarrevolución en la independencia de México 1767- 1867 (2013). de Chilpancingo y de los planteamientos de la Constitución de Apatzingán?, ¿de la valiente participación de los diputados novohispanos en las Cortes de Cádiz en defensa de la igualdad de representación y del derecho a la ciudadanía de las castas con sangre africana, de la abolición de la esclavitud, de la libertad de imprenta, de comercio, de los derechos del hombre?, ¿de las propuestas de unión entre realistas e insurgentes, de españoles peninsulares y americanos de la II Condesa de Regla en 1815, de la misma idea expuesta a Vicente Filisola en 1815 por Agustín de Iturbide y por Xavier Mina, Pedro Moreno y sus compañeros en 1817?, ¿de la lucha continuada en las montañas del sur con Vicente Guerrero y sus seguidores?

¿No será más bien que los veteranos de la guerra civil iniciada en 1810 eran los menos entusiastas en continuar con enfrentamientos y destrucción por doquier? ¿Los miembros del Ejército de las Tres Garantías, el primer ejército mexicano, resultado de la fusión de ex insurgentes, ex realistas e indultados, casi todos nacidos en la Nueva España, no serían los más interesados en una paz negociada para alcanzar la independencia de su patria, sin recurrir a la violencia, a la muerte y al sufrimiento de sus familias y comunidades? Veamos si podemos dar respuesta a estas preguntas a la luz de hechos comprobados.

\section{Tres olas revolucionarias}

Es importante señalar que se olvida el contexto del mundo atlántico del periodo 18201848. Ya no son los años 1808, 1810, 1812, 1815 o 1817, aunque ciertamente las vivencias de esos años están presentes en el imaginario de la generación consumadora de la independencia, pero precisamente en 1820 se inició la primera de tres olas revolucionarias: la de 1820 y las otras dos, la de 1830 y la de 1848, en ambos lados del Atlántico. Esa época es conocida como "La Primavera de los Pueblos" (Soriano Blasco, 2021).

En este breve bosquejo de una época tan dinámica de la historia universal sólo nos centraremos en esta primera ola revolucio- 
naria, aquella en que quedó inmersa la consumación de la independencia de la Nueva España y el nacimiento del Estado mexicano: en esa segunda década del siglo XIX en la que el ejército y el clero fueron protagonistas destacados de los movimientos revolucionarios, no sólo en Nueva España sino en muchos pueblos del Atlántico.

El 1 de enero de 1820 se inicia en España la rebelión del coronel Rafael del Riego (17941823), pronunciamiento que se convirtió en símbolo de la revolución liberal en Europa y América en la segunda década del siglo XIX. Sánchez Martín ha escrito que Riego "refleja los deseos de los militares más progresistas del momento" (Sánchez Martín, 2016) y siempre manifestó un escrupuloso respeto a las normas constitucionales. Se opuso a combatir a los insurgentes de la América Hispánica con las armas y él y sus compañeros exigieron a Fernando VII la vuelta al orden constitucional. Después de lo ocurrido en España, se sucedió una serie de revoluciones mediante pronunciamientos militares que exigían demandas liberales; entre ellas, sufragio, igualdad, libertad de prensa, libertad de comercio, una monarquía constitucional y un rey o monarca ya hecho (Soriano Blasco, 2021). Irene Castells, por su parte, escribe que la Constitución de Cádiz fue aceptada por muchos "como bandera frente al absolutismo restaurado" (1989: 85), sobre todo porque no presentaba aspectos de ser impía y regicida como la revolución de Francia: la española era una constitución católica y monárquica, más cercana a los habitantes de Nápoles, el Piamonte, Portugal, a los ortodoxos griegos y a los dominios españoles en América. Recordemos que los pobladores de estas regiones eran católicos y cristianos ortodoxos en Grecia.

En marzo de 1821 un pequeño grupo de soldados y oficiales dirigidos por Dimitri Ypsilantes cruzó la frontera rusa y se internó en Moldavia y Valaquia. El 25 de marzo de 1821, fecha en que se celebra la independencia de Grecia, el arzobispo ortodoxo de Patras llamó a los griegos a la guerra santa contra los turcos. Una asamblea griega en Epidauro proclamó una constitución inspi- rada en la revolución de independencia de los Estados Unidos (1776-1783) y en la revolución francesa de 1789 (NG, 2015).

En 1823, George Gordon, Lord Byron (1788-1824), reunió un regimiento en apoyo a la independencia griega y se reunió con los sublevados en julio de 1823 en Missolonghi, lugar en donde murió más tarde, víctima de la malaria a la edad de 36 años (Ruiza et al., 2004).

Previamente, el 1 de julio de 1820 estalló la revolución en Nola, un pueblo cercano a Nápoles, donde un grupo de jóvenes oficiales se sublevó. Al día siguiente marchó en compañía de casi la totalidad del destacamento militar hacia Avelino, junto con unos Carbonarios, miembros de una organización secreta de liberales y constitucionales, encabezados por el abate Luigi Manichini, con el objetivo de obtener una constitución como la de Cádiz. Muchos de estos militares eran antiguos oficiales o soldados de Joaquín Murat, habían combatido como parte del ejército francés en España y admiraban el constitucionalismo español y el levantamiento de Riego (Pinto, 2020).

El caso de la revolución del Piamonte refleja también la influencia del movimiento liberal constitucional de Riego. Entre 1820 y 1823 este ejemplo se propagó por Europa "donde dio lugar al establecimiento en Nápoles, Portugal y el Piamonte, de distintos regímenes constitucionales según el patrón español" (Butrón Prida, 2012). Los revolucionarios piamonteses formaron, siguiendo lo sucedido en España, una Junta Provisional Gubernativa para defender la igualdad y la fraternidad como también ha señalado Castells (1989: 85).

La situación de la Nueva España en estos agitados años de 1820-1821 no es ajena a esta primera oleada revolucionaria atlántica como veremos más adelante, años en que se dan principalmente levantamientos militares en el Mediterráneo, inspirados en la Constitución de Cádiz y en el pronunciamiento de Rafael del Riego en enero de 1820 (Butrón Prida, 2012). 


\section{Lo rojo y lo negro}

Lo rojo: participación de militares o miembros de las milicias en conspiraciones pro independencia, 1808-1821

Si revisamos las principales etapas y los diversos proyectos emancipadores en la Nueva España postrera, encontraremos que hubo participantes militares y eclesiásticos en todos ellos y es notable cómo sus propuestas y objetivos reaparecen en 18201823. Para ello empecemos por los militares de carrera y las milicias.

\section{7-1808}

Miembros de las milicias de varias regiones del Virreinato de la Nueva España se reunieron en 1807 en Jalapa, a la espera de un intento de invasión británica. En septiembre de 1808, a raíz del Golpe de Estado contra el virrey José de Iturrigaray y del paso del gobernante preso y su familia para ser embarcados en el puerto de Veracruz, la indignación de los oficiales criollos fue profunda como lo atestiguan personajes como el capitán Ignacio de Allende y el oficial José Mariano Michelena, quienes regresaron a sus provincias molestos con el gobierno espurio de la Ciudad de México y empezaron a conspirar. Recordemos que, desde el amanecer del 16 de septiembre 1808, la Ciudad de México y el reino de la Nueva España quedaron sin autoridad legítima hasta el viernes 14 de septiembre de 1810, cuando llegó a la capital novohispana el virrey, ahora sí legítimo, Francisco Xavier Venegas. A finales de 1808, Ignacio Allende, Joaquín Arias, Mariano Quevedo y José Mariano Michelena, de regreso en sus villas y ciudades, iniciaron conspiraciones contra el gobierno ilegítimo de la Ciudad de México. Estos oficiales de milicia crearon juntas secretas en varias regiones.

\section{9}

Dos oficiales del Ejército de Nueva España visitaron al gobernador William Claiborne de Luisiana, Estados Unidos. Claiborne, en una carta a sus superiores en Washington, informó cómo en los primeros días de 1809 militares novohispanos se entrevistaron con él para sondear la posibilidad de conseguir el apoyo estadounidense para un plan de independencia.

En 1809 se preparó una conspiración en Valladolid, Michoacán. Participaron los capitanes José María Obeso, José Mariano Michelena y su hermano Nicolás, así como el oficial Mariano Quevedo, que entraron en contacto con el capitán Ignacio Allende y el oficial Mariano Abasolo, del Regimiento de Dragones de la Reina de San Miguel el Grande. Se pensó en el coronel Narciso María de la Canal, también de San Miguel, para dirigir la estrategia militar del levantamiento. En 1820, José Mariano Michelena fue uno de los oficiales que arengaron a las tropas en favor del levantamiento de Rafael del Riego por la restitución de la Constitución de Cádiz y al rechazo a embarcarse a la América española para reprimir a los insurgentes.

\section{9-1810}

Allende organizó, quizás desde 1809, la Junta Secreta de la Villa de San Miguel el Grande en donde participaron más de 60 miembros, entre ellos varios oficiales de los Dragones de la Reina. Las primeras banderas de la insurrección de 1810, según testimonio de don Félix María Calleja, pertenecían a la villa sanmiguelense y en ellas aparece la Virgen de Guadalupe en el lado principal y el Arcángel San Miguel al dorso, con el águila sobre el nopal en el lago y con armas de varios tipos. ${ }^{2}$

La Junta Secreta de San Miguel escogió, como vocero de la insurrección, al sacerdote Miguel Hidalgo y Costilla y envió comisionados a otras ciudades, entre ellas Querétaro. En dicha ciudad asistieron a la conspiración Allende, el capitán Joaquín Arias, el oficial Juan Aldama y participaron el Corregidor y su esposa. Los conjurados fueron delatados,

2 Hoy se puede apreciar una de ellas en el Museo Nacional de Historia, ubicado en el Castillo de Chapultepec, Ciudad de México; la otra permaneció en España. 
por lo cual doña Josefa Ortiz de Domínguez avisó a Allende la existencia de una orden de arresto contra él y sus compañeros.

En este sentido, se adelantó el inicio del levantamiento al domingo 16 de septiembre. Originalmente se había preparado para el 29 de septiembre, fiesta del patrono de la villa, el Arcángel San Miguel (Jiménez Codinach, 2010: 63-78).

\section{1-1814}

Presos los primeros caudillos de la insurrección en Acatita de Baján el 21 de marzo de 1811 y fusilados en Chihuahua el 26 de junio Allende, Juan Aldama y Mariano Jiménez, y el 30 de julio el padre Hidalgo, la lucha fue continuada por el secretario de Hidalgo, el licenciado Ignacio López Rayón.

En 1811 se fundó la logia masónica Lautaro número 7 en Londres y para 1812 se establecieron logias Lautaro en Cádiz, Caracas, Filadelfia, Buenos Aires, Mendoza, Santiago de Chile y en Jalapa, Veracruz, donde varios miembros de la milicia eran conspiradores. En todas ellas participaron oficiales como Carlos Alvear, José de San Martín, Simón Bolívar, Bernardo O'Higgins y otros. Eran logias patrióticas cuyo objetivo era la independencia de toda la América española.

Durante las reuniones de las Cortes de Cádiz, por lo general los diputados representantes de varias regiones de la Nueva España -a excepción de alguno, como el sacerdote Antonio Joaquín Pérez, representante de Puebla- favorecieron las posiciones del ala liberal de las Cortes. De los diputados, entre 1812 y 1814, 67 eran o habían sido militares. El 95\% de los diputados militares votó a favor de la abolición de la Inquisición, 90\% a favor de la libertad de imprenta y $80 \%$ por la abolición de los señoríos (García Godoy, 1998).

\section{5-1819}

En 1815, durante el sitio al fuerte de Cóporo, Agustín de Iturbide (1783-1824) le comentó al oficial Vicente Filisola lo fácil que sería lograr la independencia de la Nueva España si se unieran los insurgentes y los realistas en un solo ejército.

Por su parte, durante 1815 y parte de 1816 se preparó en Londres la expedición a Nueva España del joven guerrillero Xavier Mina, quien decidió llevar sólo oficiales con experiencia como apoyo a la insurgencia de la Nueva España. La mayoría de los reclutados son veteranos de las guerras napoleónicas. En Estados Unidos Mina consiguió más oficiales, algunos veteranos de la guerra entre Estados Unidos y Gran Bretaña del periodo 1812-1814. No obstante, Mina y sus compañeros fueron derrotados en 1817, por lo que este fracaso suspendió otras dos expediciones que se preparaban en Gran Bretaña para apoyar la independencia novohispana (Jiménez Codinach, 1991). Al respecto, WiIliam D. Robinson comentó que en 1817 "no había un solo regimiento criollo de los que estaban a sueldo de la España, que no estuviese preparado a seguir el estandarte de la independencia" (Robinson, 1824: 239).

Entre 1817-1818 se organizó la llamada Confederación Napoleónica en Texas, Estados Unidos. Los militares franceses, entre ellos ex generales de la Grand Armee de Napoleón I, intentaron liberar a Nueva España y traer de Santa Helena al ex emperador Napoleón I (Jiménez Codinach, 1988).

Es importante recordar, según nos advierte Patrick Puigmal, que los ex militares franceses no sólo arribaron a Estados Unidos: alrededor de 350 llegaron a Argentina, Chile y Perú; unos 200 a Nueva España y a la Capitanía general de Guatemala; 100 a Brasil y 500 a la Nueva Granada (2012: 18).

\section{0}

Anteriormente se mencionó el pronunciamiento del coronel Rafael del Riego el 1 de enero de 1820 en Cabezas de San Juan, cerca de Sevilla, y cómo participó en dicho levantamiento el oficial novohispano José Mariano Michelena, conspirador en 1809 en Valladolid, Michoacán. Las tropas que estaban destinadas a reprimir la insurgencia en Río de la Plata se negaron a ir y exigieron al rey Fernando VII el restablecimiento de la 
Constitución liberal de Cádiz. Oficiales españoles y criollos de la América española fueron iniciados en logias masónicas y en otras logias patrióticas.

Agustín de Iturbide, retirado del ejército realista desde 1816, elaboró su "Plan de Independencia de la América Septentrional" en 1820. Este Plan, recordemos, nació en el contexto atlántico de la primera ola revolucionaria, particularmente bajo el ejemplo del coronel Rafael del Riego y del oficial Antonio de Quiroga y paralelo a las revoluciones en Grecia, Nápoles, Piamonte, Portugal y en los Principados y Ducados alemanes, de carácter liberal y nacionalista iniciadas con un alzamiento militar (Carmine, 2020).

\section{1}

Iturbide convenció a Vicente Guerrero, caudillo de las montañas del sur, de unir fuerzas para lograr la consumación de la independencia. Así, con la fusión de antiguos insurgentes y realistas en el ejército trigarante se logró la Consumación, es decir, con la suma de varios esfuerzos independentistas anteriores y con el consenso de miles de ex realistas, ex insurgentes e indultados así como el apoyo de un pueblo cansado de la guerra civil, fue posible alcanzar la independencia absoluta en 1821.

Entre los criollos de 1808 que se unieron a Iturbide estaban Juan Francisco de Azcárate, defensor de la soberanía popular, y José Mariano de Sardaneta y Llorente, Segundo Marqués de San Juan de Rayas; de la época de Ignacio López Rayón, de 1811 a 1813, pasaron a la trigarancia Ramón López Rayón y Juan Raz y Guzmán, tío de Leona Vicario y dirigente de la Sociedad Secreta de los Guadalupes; de los diputados a Cortes de Cádiz, entre 1811 y 1813, serían trigarantes don José Miguel Guridi y Alcocer, liberal, Presidente de dichas Cortes y de los compañeros de Morelos son miembros del gabinete de Iturbide Andrés Quintana Roo y José Manuel de Herrera; de los oficiales de Xavier Mina se unieron a la trigarancia John Bradbun, Andrés Wöll y Jean Arago. En 1821 se unieron a Iturbide los combatientes ex insurgentes Vicente Guerrero, Nicolás Bravo, Encarnación Ortiz, El Pachón, José María Tornel, Manuel Mier y Terán, Epitacio Sánchez, Ignacio Alas y Guadalupe Victoria, así como miles de ex insurgentes indultados.

Se llegó a una unión de voluntades y al logro de la independencia por acuerdos pacíficos con oficiales realistas como Luis Quintanar, Anastasio Bustamante, Antonio López de Santa Anna, Manuel Gómez Pedraza y Pedro Celestino Negrete, quienes compartieron los objetivos de las Tres Garantías: la independencia absoluta, la defensa de la religión, una monarquía constitucional con un monarca ya hecho, la igualdad ante la ley, la ciudadanía a los indígenas, a españoles, criollos, mestizos, africanos, asiáticos, la unión de todos los ahora mexicanos, libertad de imprenta y de comercio, formación de una Junta Suprema Gubernativa, de un Congreso Constituyente de todas las provincias, un gobierno de Tres Poderes: el Ejecutivo, el Legislativo y el Judicial, entre otras propuestas. El militar liberal don Juan José Rafael O’Donojú y O’Ryan (1762-1821), último Jefe Político y Capitán General de la Nueva España, firmó el 24 de agosto de 1821 los Tratados de Córdoba con Agustín de Iturbide, aceptó el Plan de Iguala, participó en la Junta Provisional Gubernativa del Imperio Mexicano Constitucional y fue miembro de la Regencia del Imperio. Murió el 8 de octubre de 1821 y fue sepultado con honores de virrey en el Altar de los Reyes de la Catedral de México.

Otro suceso ocurrido en 1821 no debe soslayarse. Muere el 5 de mayo en Santa Helena Napoleón Bonaparte, ex emperador de Francia, el soldado tan admirado por generaciones de oficiales en Europa y América. En 1822, el primer jefe del Ejército Trigarante, Agustín de Iturbide, es elegido emperador, por unanimidad, por los diputados del Congreso Mexicano en mayo. Es coronado en julio del mismo año en la Catedral de México por el presidente del Congreso con un ceremonial inspirado en la coronación de Napoleón I. Consumación, suma de ideas, propuestas, experiencias e inexperiencias, nuevas ideas y antiguos valores, usos y cos- 
tumbres, euforia, objetivos del liberalismo inglés, francés, español, italiano, estadounidense y propios del naciente hispanoamericano, pero también se mezclan en la fundación de la patria querida, del inicio del Estado mexicano, antiguos problemas sin resolver, la bancarrota de la hacienda pública, la destrucción de puentes, caminos, silos, el gran número de huérfanos, lisiados, viudas y viudos, resentimientos, frustraciones y diferentes intereses ideológicos, políticos y económicos, resultados de 11 años de guerra civil, heridas nada fáciles de resanar.

Con la entrada a la ciudad de México el jueves 27 de septiembre de 1821 y el desfile de unos 16,000 soldados por la calle de San Francisco, se consuma la independencia de la nueva nación con el nombre oficial de Imperio Mexicano Constitucional. Nace el Ejército Imperial Mexicano, se establece las bandera nacional tricolor, probablemente inspirada en los colores de las tres virtudes teologales: blanco -fe-, verde -esperanzay rojo -caridad-; el águila fundadora de México-Tenochtitlan se convirtió así en escudo de la nueva nación; se convocó a elegir los diputados al primer Congreso Constituyente Mexicano establecido en 1822; se redactó el primer documento de Relaciones Exteriores en diciembre de 1821 y se crearon instituciones, se establecieron escuelas lancasterianas y la población, llena de ilusión, presentó un sinfín de proyectos ante las autoridades imperiales, entre ellos el voto a la mujer y su incorporación a ser miembro del Congreso (1821) (Jiménez Codinach, 2001).

\section{Lo negro: participación e influencia de eclesiásticos en los procesos de independencia de la Nueva España, 1808-1821}

El mismo ejercicio de revisión, ahora aplicado a la participación de eclesiásticos en los diversos proyectos de independencia entre 1808 y 1821, nos revela otra realidad: el apoyo de sacerdotes y religiosos al Plan de Iguala y a los Tratados de Córdoba fue en cantidad menor a la que se nos ha hecho creer. Menos número de eclesiásticos apoyaron la trigarancia que la insurrección de Allende e Hidalgo, o el periodo de Ignacio López Rayón y el de José María Morelos (1811-1815); sin embargo, algunas ideas, propuestas, objetivos y logros de los miembros del clero, activos desde 1808 hasta 1821, se reflejarán en los ideales y textos trigarantes.

En otros trabajos académicos he señalado algunos equívocos frecuentes en la historiografía nacional y extranjera sobre México, como por ejemplo llamar curas a todos los eclesiásticos, sin tomar en cuenta que cura sólo es aquel sacerdote que tiene a su cargo una parroquia, es decir, es cura párroco, cura de almas de una parroquia. De unos 7341 sacerdotes en la Nueva España en 1810, existían sólo 1072 parroquias, y no era tan fácil recibir la encomienda de una de ellas; por lo tanto, habría sólo 1072 curas párrocos y los demás eran meramente sacerdotes, del clero secular o del regular. Otro error común es considerar que la Iglesia católica es únicamente la jerarquía eclesiástica, como obispos, arzobispos, provinciales de órdenes religiosas, madres superioras de conventos, etcétera, y el bajo clero, sin reflexionar que Iglesia son todos los bautizados en la fe católica y, para el caso de la Nueva España, prácticamente era toda la población. Por tanto, la Iglesia no fue ni insurgente ni realista ni trigarante, ya que la mayoría de la población fue testigo de la guerra, pero no combatiente. Como se verá más adelante, elementos del clero diocesano y de las órdenes religiosas actuaron algunos como insurgentes, otros en defensa de la autoridad virreinal, pero, en su mayoría, fueron meros espectadores neutrales, a veces víctimas de la violencia, y en muchas ocasiones, intermediarios entre los grupos combatientes para defender a su feligresía. Edmundo O'Gorman decía que quien no conoce la Historia de la Iglesia en México no conoce la historia mexicana y ello explica por qué en una sociedad como la novohispana, la religión católica era el pilar de la convivencia y el altar y el trono eran las autoridades más respetadas por la población.

Un somero recorrido por 13 años de incertidumbre, persecuciones, venganzas y 
destrucción, pero también de lucha sincera y generosa por alcanzar la libertad, la independencia, el bienestar y la paz, la justicia y la igualdad, muestra la continua presencia del clero en la etapa postrera de la Nueva España y de su nacimiento en 1821 como nación libre y soberana.

\section{8-1809}

Fray Melchor de Talamantes (1765-1809), mercedario peruano nacido en Lima el mismo año que José Morelos y Pavón (17651815), llegó a la Nueva España en 1799. Era doctor en Teología por la Universidad de San Marcos y amigo del precursor de la independencia peruana, el doctor Hipólito Unanue (Pampillo, 2020).

Talamantes participaba en las tertulias del marqués de Guardiola, conspirador en pro de la independencia de la Nueva España en 1785, y de José Mariano de Sardaneta, marqués de San Juan de Rayas, cercano a Ignacio Allende, acusado por las autoridades virreinales de 1810, de ser "el principal corifeo de la insurrección" de aquel año. Este fraile mercedario era un ilustrado, conocedor del latín, griego, francés, inglés y vasco, de filosofía, historia, física, geografía, medicina, derecho, teología y lector de autores como Voltaire, Rousseau, Montesquieu y Adam Smith (Pampillo, 2020).

Entre otras ideas, fray Melchor escribió:

Aproximándose ya el tiempo de la independencia de este reino, debe preocuparse que el Congreso que se forme lleve en sí mismo, sin que pueda percibirse de los inadvertidos, las semillas de esa independencia sólida, durable y que pueda sostenerse sin dificultad y sin efusión de sangre (Pampillo, 2020: 390). ${ }^{3}$

Tres propuestas de Talamantes aparecen, de alguna manera, en el Plan de Iguala: creación de una Junta de representantes del reino, la necesidad de un Congreso y el intento de lograr "un espíritu de unión" (Jiménez Codinach, 1997).

3 Nótese que los siguientes términos de 1808 -Independencia, Reino, Congreso, Independencia sin efusión de sangre- volverán a aparecer en 1820-1823.
En el verano de 1809 se conspiraba en Valladolid, cabeza de la diócesis más progresista de la Nueva España, que comprendía los actuales estados de Michoacán, Guanajuato y San Luis Potosí. Entre los conspiradores se encontraba el sacerdote Manuel de la Torre Lloreda (1786-1836), poeta y escritor, quien había estudiado en el Seminario Tridentino de Valladolid y llegó a ser cura párroco de Santa Clara y de Pátzcuaro. Por su participación en la conspiración de VaIladolid en 1809 estuvo preso en el Convento del Carmen y en el de San Diego de la misma ciudad. En 1813 describió la pobreza de sus feligreses de Pátzcuaro y, en 1817, las dificultades para impartir los sacramentos debido al caos de la guerra civil. En 1821 apoyó la trigarancia y defendió la monarquía constitucional, ya que ofrecía grandes ventajas: unidad de mando, estabilidad sin despotismo y "democracia en razón del derecho al voto y a la acción popular mediante la prensa libre" (Wikipedia, 2021). El 12 de diciembre de 1821 ofreció el "Discurso que en la Misa de Gracias en la Iglesia Mayor de la ciudad de Pátzcuaro el día 12 de diciembre de 1822, a consecuencia de la aclamación religiosa del Señor Don Agustín Primero, emperador de México", impreso por el Ayuntamiento Constitucional de Pátzcuaro (Torre Lloreda, 1822).

\section{0-1815}

Fue en el Obispado de Michoacán donde se rebelaron varias ciudades y villas contra la expulsión de los jesuitas en 1767, entre ellas Guanajuato, Pátzcuaro, San Luis de la Paz y San Luis Potosí. Todas ellas sufrieron cruenta represión por defender a sus religiosos. No sorprende que sea en esta región de la Nueva España, en esta diócesis de vanguardia y de conciencia social, donde se inició la insurrección de 1810, donde tuvo lugar el mayor número de batallas y de donde fueron originarios los principales caudillos, Ignacio Allende, Miguel Hidalgo, Ignacio y Juan Aldama, José Mariano Jiménez, Nicolás Zapata, Mariano Abasolo, Ignacio y Ramón López Rayón, José María Morelos 
y el primer jefe de la Trigarancia, Agustín de Iturbide, entre otros muchos destacados participantes en la guerra civil de 11 años.

El virrey Francisco Xavier Venegas escribía lo siguiente al Ministro de Guerra el 27 de enero de 1811:

La ciudad de Valladolid ha sido el origen de la revolución y el constante foco de ella [...] El clero secular y regular de aquella ciudad, empezando por la mayor parte de los prebendados de su catedral, han apoyado las ideas revoltosas y disparatadas del cura Hidalgo, quien tienen por oráculo (Bravo Ugarte, 1966: 87).

En agosto de 1811 Ignacio López Rayón, secretario del padre Hidalgo y su sucesor en la causa insurgente, creó la Junta Gubernativa de América en Zitácuaro, antecedente de la Junta Provisional Gubernativa de 1821. Los propósitos de esta Junta eran defender los derechos al trono de Fernando VII y preparar unos Elementos Constitucionales que, al igual que la Constitución de Cádiz y la de Apatzingán, establecían la primacía de la religión católica como la única de la nación. Varios simpatizantes de la insurgencia en estos años se unieron a la trigarancia en 1821, entre ellos el sacerdote José Sixto Berduzco, compañero de Morelos en el Seminario, y el padre José Manuel Sartorio, muy cercano a Leona Vicario. Al extenderse por Europa el modelo constitucional de 1812, la Nueva España no fue ajena a su influjo.

Paralelamente a la insurrección de 18101813, se produjo una revolución de conciencias a través de las Cortes de Cádiz. La mayoría de los diputados novohispanos en este cuerpo parlamentario son liberales, a excepción del sacerdote Antonio Pérez de Puebla. Lo aprendido en Cádiz, gracias al padre José Miguel Guridi y Alcocer, quien fue presidente de las Cortes, lo preparó para que entre 1821 y 1822, como miembro de la Junta Provisional Soberana, elaborara un proyecto de Constitución para el Imperio Mexicano Constitucional.

Por otro lado, el obispo electo de Michoacán, Manuel Abad y Queipo, ilustrado y liberal, escribía en 1812 que la insurrección de 1810 era "obra casi propia de los eclesiásticos, pues que ellos son los principales autores, y los que la han promovido y sostienen" (Bravo Ugarte, 1966: 86-90) y la realidad que se vivió en la Nueva España avalaba esta visión: en 1810 participaron en la insurgencia sacerdotes diocesanos como el propio Miguel Hidalgo, José María Morelos, Mariano Matamoros, José María Cos, José Sixto Berduzco, Marcos Castellanos y José María Mercado, entre otros.

Con José María Morelos (1765-1815) y sus compañeros sacerdotes, como José María Berduzco, José María Cos, Mariano Matamoros y José Manuel de Herrera, el movimiento trigarante sostuvo la defensa de la religión, la inmunidad eclesiástica, la independencia absoluta de España, la igualdad ante la ley de todos los sectores sociales, la devoción guadalupana, entre otros. Recordemos que fueron tres sacerdotes, doctores en teología, quienes editaron periódicos en la época de Morelos: José Manuel de Herrera, Vicario General Castrense nombrado por el Siervo de la Nación, José María Cos y José de San Martín (Herrejón Peredo y Mejía Zavala, 2018: 14).

Asimismo, Isidro Ignacio de Icaza, jesuita en 1816, rector de la Universidad de México, miembro de la Junta Provisional Soberana de 1821 y firmante del Acta de Independencia, y José Manuel de Herrera, tan cercano a Morelos, coautor de la Constitución de Apatzingán, enviado a Estados Unidos como representante del Congreso insurgente, tutor de Juan Nepomuceno Almonte, hijo de Morelos, sería más tarde trigarante y Ministro de Relaciones Interiores y Exteriores del Primer Imperio Constitucional Mexicano. Todos los que lucharon por la independencia, de 1810 a 1821, pidieron el regreso de los jesuitas a Nueva España y luego al México Independiente.

\section{$1817-1819$}

Con Xavier Mina y los ex diputados liberales españoles exiliados en Londres, se tuvo fe en el régimen constitucional. El temor a las monarquías absolutas, la participación 
de oficiales veteranos de las guerras europeas y de Estados Unidos en la expedición auxiliadora y el énfasis en que sólo la unión de realistas e insurgentes podría conseguir la anhelada independencia, produjeron confianza.

Entre los eclesiásticos, representantes de lo negro, existe uno que destaca por la gran influencia que tuvo en la consumación de la independencia de Nueva España, especialmente en el Plan de Iguala: el padre Servando Teresa de Mier, quien acompañó a Mina desde Inglaterra y Estados Unidos a la Nueva España en 1817. Estando preso en San Juan de Ulúa, escribió que 200 ejemplares de la obra del abate Dominique de Pradt, ex Arzobispo de Malinas (nunca confirmado), De las Colonias y de la Revolución Actual de la América (1817), habían llegado a Veracruz y anotaba que temía que hubieran influido en el plan de Iturbide. ¿Quién era el autor de esta obra tan leída tanto en Europa como en América?

Dominique Georges Frederique de Riom de Prolhiac de Fourt de Pradt nació en el Castillo de Pradt en Auvernia el 23 de abril de 1759. Fue ordenado sacerdote en junio de 1784, se distinguió como diputado por Rouen en los Estados Generales y como miembro de la Asamblea Francesa. Como integrante de esta última se opuso terminantemente a la Constitución Civil del Clero promulgada en 1790. Por ser antirrevolucionario se vio obligado a emigrar al extranjero y vivió en Bruselas, luego en Münster y en Hamburgo, población esta última en donde publicó su primer libro: L'Antidote au Congres de Radstadt en 1798. Regresó a Francia en 1800 y su pariente el general Duroc, amigo cercano de Napoleón Bonaparte, le brindó su apoyo. En 1802 publicó Les trois Ages des Colonies ou Leurs Etats Passe, Present et à Venir, obra leída por muchos hispanoamericanos y angloamericanos, entre ellos Simón Bolívar, Bernardino de Rivadavia, Thomas Jefferson y John Adams. Napoleón lo nombró su capellán privado y Pradt le correspondió llamándose a sí mismo "Capellán del Dios Marte".
El abate analizó los acontecimientos más relevantes de su época y dejó escritas 15 obras sobre la independencia de las colonias. Para la historia de México debemos señalar que Pradt fue una de las principales fuentes que inspiraron el "Plan de independencia de la América Septentrional", conocido como "Plan de Iguala" (Jiménez Codinach, 1982). ${ }^{4}$

Nuestro abate, después de haber sido un emigrado contrarrevolucionario, se convirtió, poco a poco en un destacado escritor liberal, crítico de Bonaparte, de Carlos IV y Fernando VII y de las autoridades eclesiásticas que no quisieron confirmar su nombramiento como arzobispo de Malinas. Pradt, considerado "quintaesencia del liberalismo" y muy popular entre los liberales franceses de la década de 1820, fue leído y apreciado por los caudillos sudamericanos de la independencia, como Simón Bolívar (quien lo invitó a residir en Colombia y a convertirse en Patriarca de las Indias), José de San Martín, Bernardino de Rivadavia (quien lo conoció en Francia) y Bernardo O'Higgins, el prócer chileno (Jiménez Codinach, próximamente).

Respecto a México, este sacerdote veía inaplazable su independencia: así como es imposible que la bellota deje de venir a ser con el tiempo una encina, proponía a la América Española una separación absoluta de España, pero preparada, sin violencia. Planteaba el establecimiento de monarquías constitucionales -por entonces el modelo político de las revoluciones liberales- y que los americanos formaran un pacto de familia con España a través de príncipes de la familia real en los tronos americanos. Estas ideas fueron muy comentadas en esos años, al grado que el padre Mier llamó al Plan de Iguala "el hijo espiritual de Pradt" (Jiménez Codinach, 1984: 686). Lorenzo de Zavala, testigo de conversaciones y discusiones de la época, anotó lo siguiente:

4 Soberanes Fernández señala al respecto: "de ser cierta la tesis de Jiménez Codinach, este hecho no hace sino añadir a la nuestra, pues De Pradt sería un puente directo entre el liberalismo conservador de Edmund Burke y la intelectualidad novohispana de 1820" (2019: 191). 
No debo omitir hacer mención honorífica del ilustre arzobispo de Malinas M. de Pradt, cuyos escritos contribuyeron en gran manera a ilustrar a muchos jefes mexicanos que sirvieron antes al gobierno español y posteriormente a la independencia de su patria (Zavala, 1845: 79).

Pradt promovía con insistencia en sus libros la necesidad de la unión: "el mayor de los males -escribía- (...) es la división" (Pradt, 2011: 137-138); señalaba la importancia de la religión católica, pues como Napoleón había obrado con inteligencia al firmar el Concordato de la República Francesa con el Papa Pío VII en 1801, "con la religión se le vio [a Francia] entrar de nuevo en el orden social" (Pradt, 2011: 137-138). Y sería México quien, con el establecimiento del Primer Imperio Constitucional en 1821, se convertiría en el único país hispanoamericano que realizaría el plan de separación preparada y de una monarquía constitucional propuesto por Pradt con tanto énfasis.

El primer documento elaborado en diciembre de 1821 por la Comisión de Relaciones Exteriores del Imperio Mexicano proponía, en el caso de Francia, que se levantara en alguna plaza de la ciudad de México una estatua a Monseñor de Pradt, por sus insignes servicios a la causa de la independencia (Jiménez Codinach, 1982).

\section{0-1821}

El Plan de Iguala, que recoge experiencias de la insurgencia y de la contrainsurgencia, del liberalismo español, del inglés, francés, estadounidense y de los ordenamientos jurídicos tradicionales hispánicos, es un documento compuesto y mestizo como el México independiente. Los artículos más importantes, según la Comisión de Justicia del Imperio Mexicano, son el primero, el segundo, el tercero y el décimo segundo, es decir, la religión católica sin tolerancia de alguna otra, misma tesis de la Constitución de Cádiz (1812), de la Constitución de Apatzingán (1814) y de la Constitución Federal de los Estados Unidos Mexicanos (1824), la cual afirma en el artículo 3을
La religión de la nación mexicana es y será perpetuamente la católica, apostólica, romana. La nación la protege por leyes sabias y justas, y prohíbe el ejercicio de cualquier otra (Cámara de Diputados, 1824: 77).

Proclamaba además la absoluta independencia de España, un gobierno monárquico templado por una constitución análoga al país, la igualdad de todos los habitantes del Imperio, la posibilidad de obtener cualquier empleo sin necesidad de probar hidalguía, sólo por mérito y virtud" (Jiménez Codinach, 2002: 423). Y para aquellos que presentan el Plan de Iturbide como anticonstitucional, preparado por un grupo de serviles, es decir, antiliberales de la Casa Profesa, el lector puede leer el artículo 21 de dicho Plan: "Interin las Cortes (o Congreso mexicano) se establecen se procederá en los delitos con total arreglo a la Constitución española" (Almonte, 1821). Y el 23 de junio de 1821, al entrar a Cuernavaca, Iturbide fue muy claro: "La Constitución Española en la parte que no contradice nuestro sistema de independencia, arregla provisionalmente nuestro gobierno mientras los diputados de nuestras provincias se reúnan y dicten lo que más conviene a nuestra felicidad social" (Jiménez Codinach, 1984: 696).

\section{Conclusiones}

La realidad de lo sucedido entre 1820 y 1821, como se desprende de estas páginas, es que la consumación de la independencia no fue obra de una contrarrevolución, ni resultado de los grupos más retrógrados -como se describen al clero y a los militares-, sino todo lo contrario, pues entre sus filas, desde 1808 hasta 1821, se encuentran personas de ideas avanzadas, de conciencia social, de amor a la libertad y sólo la ignorancia de sus trayectorias y de sus acciones y logros explican que se siga distorsionando el movimiento trigarante, a la obra de Iturbide y de sus compañeros como Vicente Guerrero, los ex insurgentes, los ex realistas, los indultados y el apoyo entusiasta de la población en general, a quienes se les debe el nacimiento de 
México independiente, logrado de manera pacífica, plena de euforia y alegría.

Fue en este espíritu de consenso, de suma de propuestas y de la participación de personajes en las distintas etapas del proceso emancipador, de la presencia de hondas raíces culturales de una población multiétnica, multicultural, sociedad más religiosa que la de España -a decir de José María Morelos-, con militares, eclesiásticos, abogados, intelectuales, periodistas, funcionarios, maestros, comunidades indígenas, artesanos, mujeres, jóvenes, ancianos, abiertos a la posibilidad de ser libres e independientes, a la representación, a la defensa de los derechos del Hombre, a la libertad de expresión, de prensa, el derecho a la ciudadanía, a la felicidad, a la paz y el bienestar - valores que se anhelaban en las ciudades, las universidades, en pueblos y villas, en los corrillos y tertulias de Europa y de la América española y particularmente en la postrera Nueva España- donde finalmente, un jueves 27 de septiembre de 1821, los pobladores reían y lloraban de emoción, cantaban en las calles y paseos adornados de los colores trigarantes, oían las campanas de todas las iglesias de la Ciudad de México repicar de gozo y lanzaban iVivas! al Ejército de las Tres Garantías, en uno de los días más felices del México independiente. No es de sorprender que, en la lejana Francia, el abate de Pradt, eclesiástico liberal francés, autor de vanguardia en su época, traducido al inglés, castellano, italiano, ruso, polaco y sueco, escribiera eufórico al conocer las noticias de la consumación de la independencia de México en 1821:

iMéxico, convertido en imperio constitucional! Un rey de Europa y toda su familia hasta la extinción de ésta, convidados a abandonar la tierra que produjo los conquistadores del trono de los Moctezumas y a que vayan a sentarse en lugar de éstos [...] es verdad que todo esto se parece mucho a las Mil y Unas Noches y la historia de nuestros días realiza los cuentos del Oriente (Pradt, 1822).

\section{Fuentes consultadas}

Almonte, J.N. (1821), Plan de Independencia de la América Septentrional (Plan de Iguala), Ciudad de México, Biblioteca Digital Mexicana, <https://cutt.ly/ $\mathrm{Xm} \times 4 \mathrm{Wja}>$, 14 de enero de 2021.

Bravo Ugarte, José (1966), "El clero y la independencia", en Temas históricos diversos, Ciudad de México, Editorial Jus.

Butrón Prida, Gonzalo (2012). "La inspiración española de la revolución piamontesa de 1821", Historia constitucional: Revista Electrónica de Historia Constitucional, núm. 13, Universidad de Oviedo, pp. 73-97, <https://cutt.ly/emxkNUa>, 4 de febrero de 2021.

Cámara de Diputados (1824), Constitución federal de los Estados Unidos Mexicanos, Ciudad de México, Cámara de Diputados, <https://cutt.ly/Amx8WOS>, 4 de febrero de 2021.

Castells, Irene (1989), La utopía insurreccional del liberalismo, Barcelona, Crítica.

Flores Caballero, Romeo (2013), Revolución y Contrarrevolución en la independencia de México 1767-1867, Ciudad de México, Océano.

Flores Caballero, Romeo (1969), La Contrarrevolución en la independencia de México: los españoles en la vida política, social y económica de México, (18041838), Ciudad de México, El Colegio de México.

García Godoy, María Teresa (1998), Las Cortes de Cádiz y América. El primer vocabulario liberal español y mejicano (1810-1814), Sevilla, Servicio de Publicaciones de la Diputación.

Herrejón Peredo, Carlos y Mejía Zavala, Eugenio (2018), Diputados Constitucionales del Supremo Congreso Mexicano, octubre 1814-diciembre 1815, Morelia, H. Ayuntamiento de Morelia/ Archivo Histórico Municipal de Morelia. 
Jiménez Codinach, Guadalupe (próximamente), "El contexto internacional del 'Plan de Independencia de la América Septentrional' conocido como Plan de Iguala (1816-1824)".

Jiménez Codinach, Guadalupe (2010), "De Alta lealtad: Ignacio de Allende y los sucesos de 1810-1811", en Marta Terán y José Antonio Serrano Ortega (eds.), Las Guerras de independencia de la América Española, Zamora, El Colegio de Michoacán.

Jiménez Codinach, Guadalupe (2002), "Con abrazos y no a balazos: consenso y guerra civil en la Independencia Novohispana, 1808-1821", en Alberto Carrillo Cázares (ed.), La Guerra y la Paz. Tradiciones y contradicciones, Vol. II, Zamora, El Colegio de Michoacán.

Jiménez Codinach, Guadalupe (2001), México: los proyectos de una nación: 18211888, Ciudad de México, Fomento Cultural Banamex, A.C.

Jiménez Codinach, Guadalupe (1997), México: su tiempo de nacer, 1750-1821, Ciudad de México, Fomento Cultural Banamex, A.C.

Jiménez Codinach, Guadalupe (1991), La Gran Bretaña y la independencia de México, 1808-1821, Ciudad de México, Fondo de Cultura Económica.

Jiménez Codinach, Guadalupe (1988), "Confederatión Napoléonnie. El desempeño de los conspiradores militares y las sociedades secretas en la Independencia de México", Historia Mexicana, 38 (1), Ciudad de México, El Colegio de México, pp. 43-68.

Jiménez Codinach, Guadalupe (1984), "La Insurgencia. Guerra y Transacción, 1808-1821", vol. V, México y su Historia, 12 vols., Ciudad de México, UTEHA.

Jiménez Codinach, Guadalupe (1982), México en 1821. Dominique de Pradt y el Plan de lguala, Ciudad de México, Universidad Iberoamericana/Ediciones El Caballito.
NG (National Geographic) (2015), "La gran revolución griega contra el Imperio Otomano", historia.nationalgeographic. com.es, <https://cutt.ly/4mxfFFV>,14 de enero de 2021.

Pampillo Boliño, Juan Pablo (2020), "Talamantes y su proyecto para la independencia de México y la creación de una comunidad de reinos hispánicos", Revista de Historia de América, núm. 158, Ciudad de México, Comisión de Historia del Instituto Panamericano de Geografía e Historia, pp. 381-402, <https://cutt.Iy/1mxHFyM>, 9 de octubre de 2020.

Patrice Gueniffey (2018), Bonaparte, 17691802, traducción de José Andrés Ancona Quiroz, revisada por Fausto José Trejo, Ciudad de México, Fondo de Cultura Económica.

Patrick Puigmal (2012), "Napoleónicos, europeos y liberales en la independencia americana: dos casos de estudio: Chile y México", Tiempo Histórico, núm. 5, Santiago de Chile, Universidad Academia de Humanismo Cristiano, pp. 15-35, <https://cutt.ly/MmXRIKY>, 4 de febrero de 2021.

Pinto, Carmine (2020), "1820-1821. Revolución y Restauración en Nápoles. Una interpretación histórica", Berceo. Revista Riojana de Ciencias Sociales y Humanidades, núm. 179, La Rioja, Instituto de Estudios Riojanos, pp. 43-58, <https:// cutt.Iy/ImxjGEg>, 4 de febrero de 2021.

Pradt, Dominique de (2011), Les Quatre Concordats: Suivis de Considerations Sur Le Gouvernement de L'Eglise En General, Et Sur L'Eglise de France En Particulier Depuis 1515..., París, Nabu Press.

Pradt, Dominique de (1822), La Europa y la América en 1821, Burdeos, Juan Pinard Impresor.

Pradt, Dominique de (1817), De las Colonias y de la Revolución Actual de la América, Burdeos, Juan Pinard Impresor. 
Quirarte, Martín (1995), Visión Panorámica de la Historia de México, Ciudad de México, Porrúa.

Rivera, María (1999), "Fin de siglos. Entrevista al historiador Luis González y González", La Jornada, martes 12 de agosto, Ciudad de México, Demos, Desarrollo de Medios.

Robinson, William Davis (1824), Memorias de la revolución de Mégico, Londres, Poppin's Court.

Ruiza, M.; Fernández, T. y Tamaro, E. (2004), "Biografía de Lord Byron", en Biografías y vidas. La Enciclopedia Biográfica en línea, Barcelona, biografiasyvidas. com, <https://cutt.ly/Imxggso>, 6 de febrero de 2021.

Sánchez Martín, Víctor (2016), "Rafael del Riego, símbolo de la revolución liberal”, Tesis de doctorado Universidad de Alicante, Alicante, <https://cutt.ly/fmxdoyk>, 2 de febrero de 2021.

Soberanes Fernández, José Luis (2019), "El Plan de Iguala o el Origen del Estado Mexicano", en Una historia constitucional de México, T. I, Ciudad de México, UNAM-Instituto de Investigaciones Jurídicas.

Soriano Blasco, Gonzalo (2021), "1848: la Primavera de los Pueblos", archivoshistoria.com, <https://cutt.ly/VmxoUO>, 2 de febrero de 2021.

Stendhal (2015), Rojo y Negro, traducción de Antonio Vilanova, introducción de Michel Crouzet, Barcelona, Penguin Random House, edición Kindle.

Torre Lloreda, Manuel de la (1822), "Discurso que en la Misa de Gracias en la Iglesia Mayor de la ciudad de Pátzcuaro el día 12 de diciembre de 1822, a consecuencia de la aclamación religiosa del Señor Don Agustín Primero, emperador de México", Ciudad de México, Imprenta Imperial del Sr. Alejandro Valdés.

Wikipedia (2021), "Manuel de la Torre Lloreda", San Francisco, Fundación Wiki- pedia Inc., <https://cutt.ly/ymxCxmx>, 25 de octubre de 2020.

Zavala, Lorenzo de (1845). Ensayo Crítico de las Revoluciones de México, desde 1808 hasta 1830, Ciudad de México, Imprenta de Manuel N. de la Vega.

Recibido: 8 de marzo de 2021. Reenviado: 3 de mayo de 2021. Aceptado: 14 de mayo de 2021.

\section{Guadalupe Jiménez Codinach}

Es licenciada y maestra en Historia por la Universidad Iberoamericana, doctora en Historia por la Universidad de Londres (University College). Ha sido profesora e investigadora del Departamento de Historia de la Universidad Iberoamericana y asesora de Fomento Cultural Banamex, A.C.; ha realizado trabajos de curaduría para este organismo y diversos museos mexicanos y tiene numerosas publicaciones sobre la historia de México del siglo XV al XIX. Actualmente está en prensa su más reciente investigación: "El contexto internacional del 'Plan de Independencia de la América Septentrional' conocido como Plan de Iguala (1816-1824)". 


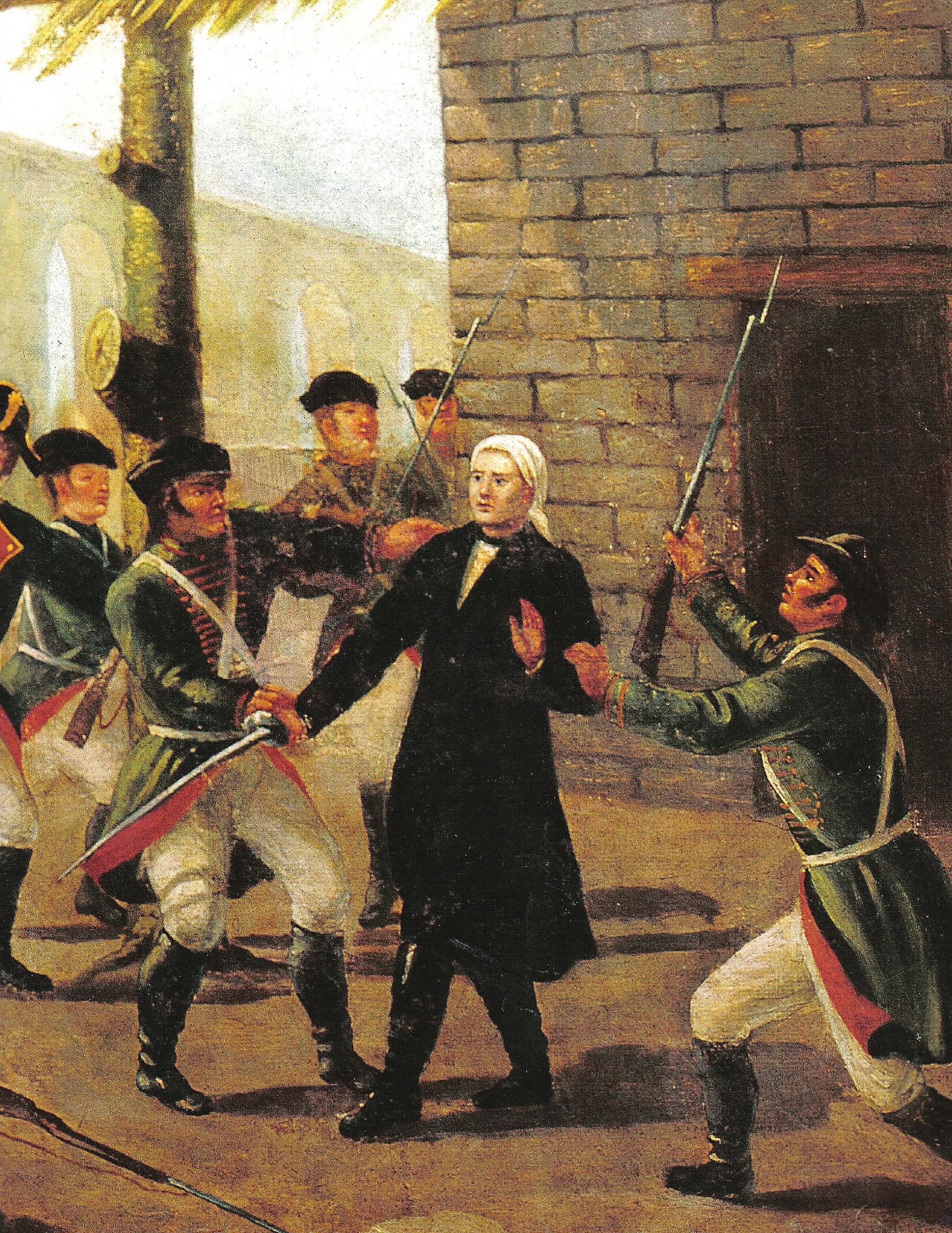

